\title{
Pericardiectomy for constrictive pericarditis in a resource constraint setting
}

\author{
Isaac Okyere ${ }^{1,2}$, Perditer Okyere ${ }^{3}$, Emmanuel Ameyaw ${ }^{4}$, Samuel Gyasi Brenu², Martin Tamatey ${ }^{5}$, \\ Francis Agyemang Yeboah ${ }^{6}$ \\ ${ }^{1}$ Department of Surgery, Kwame Nkrumah University of Science, Kumasi, Ghana \\ ${ }^{2}$ Directorate of Surgery, Komfo Anokye Teaching Hospital, Kumasi, Ghana \\ ${ }^{3}$ Department of Medicine, Kwame Nkrumah University of Science, Kumasi, Ghana \\ ${ }^{4}$ Department of Child Health, Kwame Nkrumah University of Science and Technology, Kumasi, Ghana \\ ${ }^{5}$ Department of Surgery, University of Health and Allied Sciences, Ho, Ghana \\ ${ }^{6}$ Department of Molecular Medicine, Kwame Nkrumah University of Science and Technology, Kumasi, Ghana \\ Kardiochirurgia i Torakochirurgia Polska 2021; 18 (3): 165-172
}

\begin{abstract}
Introduction: Constrictive pericarditis is the endpoint of the natural history of acute pericarditis of different aetiologies where a chronic inflammatory process results in a thickened, fibrotic and inelastic pericardium with consequent impairment of diastolic function and systemic congestion.

Aim: To evaluate the clinical features, diagnosis, surgical management and outcome of patients with constrictive pericarditis as managed in a local setting of a tertiary hospital in Ghana.

Material and methods: A retrospective review of the medical records of patients who had undergone pericardiectomy for constrictive pericarditis at a teaching hospital.

Results: Ten patients underwent pericardiectomy for the period of study. There were $8(80 \%)$ males and $2(20 \%)$ females. The mean age was $20.4 \pm 17.2$ years. Six of the patients 6 (60\%) were in NYHA class III. Preoperative diagnostics included chest X-ray, echocardiography, and computed tomography scan. The surgical approach for the pericardiectomy was median sternotomy. The mean operative time was $159.9 \pm 43.0 \mathrm{~min}$. The mean postoperative days spent before being discharged was $6.9 \pm 2.3$ days. Nine (90\%) of the patients were in NYHA class I after a mean follow-up of $19.3 \pm 16.7$ months. One patient died 6 weeks after surgery with heart failure and one patient was lost to follow-up.

Conclusions: Surgical pericardiectomy via median sternotomy is still the standard modality of treatment for constrictive pericarditis with excellent results even in resource constraint settings.
\end{abstract}

Key words: median sternotomy, pericardiectomy, constrictive pericarditis, tuberculosis.

\section{Introduction}

Constrictive pericarditis is a chronic inflammatory process of the pericardium that leads to progressive pericardial fibrosis encasing the heart in a thickened fibrotic pericardium [1]. This can result in impaired diastolic cardiac function leading to heart failure. Clinically, constrictive pericarditis manifests as systemic pulmonary congestion, abdominal distension from ascites, tender hepatomegaly or bipedal oedema. It is a rare condition, with 366 reported cases from the Mayo Clinic over a 60-year period [2].

\section{Aim}

This current study assesses the surgical management of constrictive pericarditis over a 5 -year period in a tertiary teaching hospital in Ghana.

\section{Material and methods \\ Study site/design}

A cross sectional retrospective cohort study of the medical records of 10 consecutive patients who had undergone pericardiectomy for constrictive pericarditis at the Komfo Anokye Teaching Hospital (KATH) between January 1, 2015 and June 31, 2020 were analysed. KATH is the second largest hospital in Ghana with a 1000 bed capacity with a recently established Cardiovascular and Thoracic Surgery Unit.

\section{Collection of retrospective data}

We manually collected the data of 10 consecutive patients who had undergone pericardiectomy for constrictive pericarditis at the KATH between January 1, 2015 and June

Address for correspondence: Isaac Okyere MD, FWACS, FGCS, Department of Surgery, Kwame Nkrumah University of Science, Kumasi, Ghana, phone: +233208168512 , e-mail: isaac.okyere@knust.edu.gh

Received: 20.04.2021, accepted: 4.07.2021. 


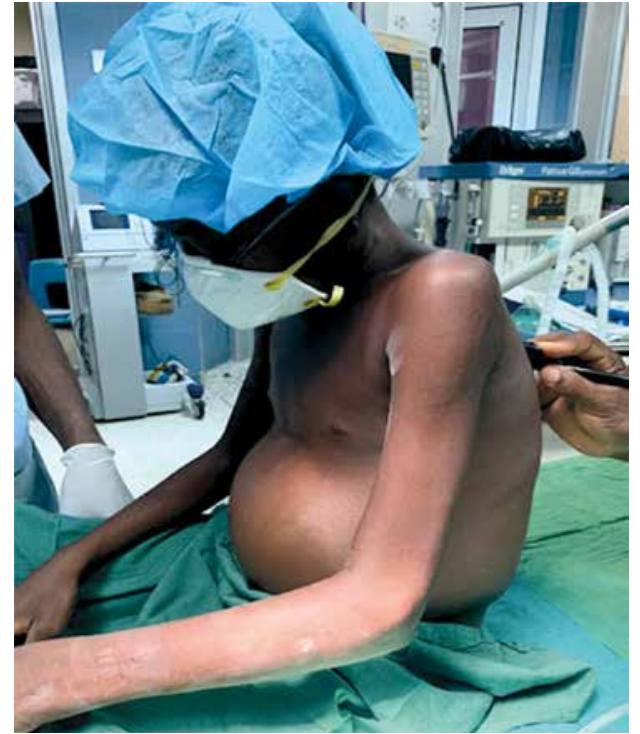

Figure 1. Patient in theatre with massive abdominal distension

31, 2020. Patients' data were retrieved from the operating theatre books and the patient's folder noting the clinical presentation, diagnostic investigations including chest $X$-ray (CXR), echocardiography, and chest computed tomography $(C T)$ scan, intraoperative findings and histopathological evaluation of the excised pericardium.

\section{Data analysis}

Data were analysed with SPSS Statistics software version 22.0 (IBM Corp. Armonk, NY, USA). Sociodemographic, clinical variables including preoperative diagnosis, intraoperative and postoperative clinical variables were presented as means, ranges, frequency and percentages with simple tabulation.

\section{Follow-up}

All patients were reviewed 1 week after discharge from the hospital and repeated there after 2 weeks. The reviews were carried out over a 3-month period at a 1-month interval. Subsequent reviews were scheduled depending on the clinical status of the patient.

\section{Results}

Ten patients underwent total pericardiectomy within the study period. The gender distribution of the studied subjects was 8 (80\%) males and 2 (20\%) females. The mean age was $20.4 \pm 17.2$ years with a range of 2 to 61 years. Patients were classified using the New York Heart Association (NYHA) functional and therapeutic classification into classes I-IV with $6(60 \%)$ patients being in class III and $4(40 \%)$ in class IV. Six $(60 \%)$ out of the 10 patients presented with ascites with $9(90 \%)$ of the patients having hepatomegaly. The mean duration of symptoms before presenting to the hospital was $10.6 \pm 11.1$ weeks with a range of 2 to 36 weeks. All the patients except one presented with normal sinus rhythm. Though 5 (50\%) were treated for TB preoperatively, only 3 (30\%) tested positively for TB with the remaining 7 (70\%) having non-tuberculous constrictive pericarditis. Six (60\%) of the patients underwent catheter pericardial drainage for pericardial effusion preoperatively and 5 (50\%) also had concomitant pleural effusion. Preoperative diagnostics included 9 of the 10 patients having CXR before surgery. Eight of the patients had their diagnosis confirmed from echocardiography. Only 1 patient had his diagnosis confirmed only by CT scan. Four (40\%) of the patients had their diagnosis confirmed by both echocardiography and CT scan. Two of the patients had pericardial calcification shown on the CXR and CT chest scan. The surgical approach was achieved via a median sternotomy in all patients with 1 patient undergoing the pericardial window previously before the pericardiectomy. The mean pericardial thickness was $5.6 \pm 1.4 \mathrm{~mm}$ with a range of $4-8 \mathrm{~mm}$. The mean operative time was $159.9 \pm 43.0$ minutes with a range of 112 to 257 minutes. The mean anaesthesia time was $228 \pm 38.9$ minutes within a range of 182 to 285 minutes. Only $1(10 \%)$ patient had ventilatory support postoperatively in the intensive care unit with only 3 (30\%) out of the 10 patients needing inotropic support. The mean postoperative days before discharge home was $6.9 \pm 2.3$ days within a range of 4 to 12 days. Seven (70\%) of the patients had confirmation of constrictive pericarditis from the histopathological examination of the excised pericardium. Nine (90\%) of the patients are in NYHA class I after a mean follow-up of $19.3 \pm 16.7$ months with a range of 2 to 55 months. There was no early mortality but 1 patient died 6 weeks after surgery from heart failure and one was lost to follow-up (Figures 1-3, Table I-IV).

\section{Surgical technique}

The surgical approach for all the pericardiectomies was a standard median sternotomy. A total pericardiectomy was done through the median sternotomy. Upon entering the chest, the pericardium was inspected and palpated to determine calcified areas. The thymus and pleural reflections were dissected and mobilized laterally to create a wide area of the pericardium. A centrally placed longitudinal pericardiotomy along the cephalo-caudad direction was made over the pericardium using cautery until the parietal pericardium and underlying epicardial fat were located. The incision was extended and a cleavage plane between the thickened parietal and visceral pericardium was identified as shown in Figure 4. This plane is typically avascular and superficial to the visceral pericardium. Isolated calcified areas and penetrating epicardial plaques were left. However, circumferential patches of calcified pericardium were divided with rongeurs or a thick haemostat and were carefully removed to avoid phrenic nerve and vascular injuries. The pericardium over the left ventricle was removed first, then that of the right ventricle, the aorta, the pulmonary artery, the venae cavae and finally the right atrium followed sequentially. All the pericardiectomies were performed without cardiopulmonary bypass. Half of the patients had full cardiovascular monitoring including arterial line and central venous catheter. The remaining half had only noninvasive monitoring with the central venous line. 

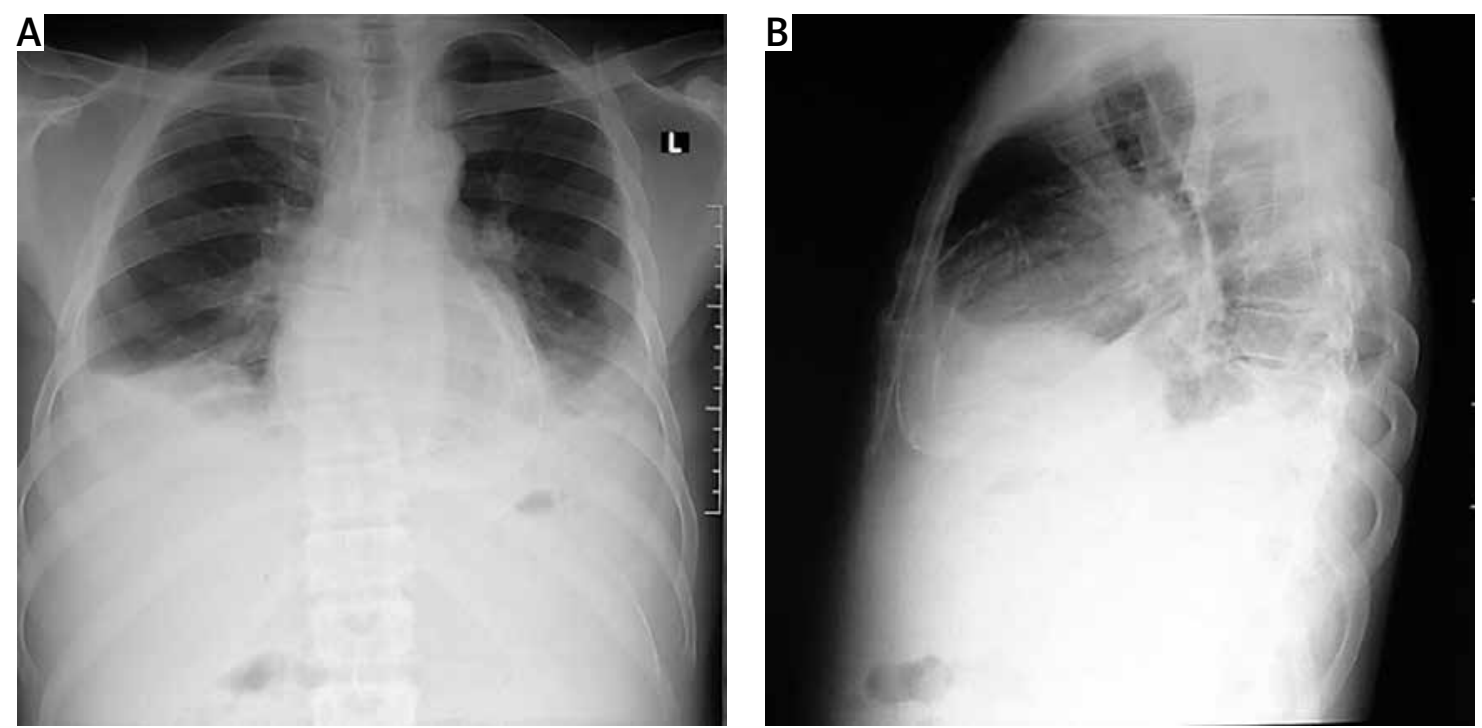

Figure 2. Chest X-ray of one of the patients with calcific constrictive pericarditis showing the pericardial calcification

\section{Discussion}

The pericardium is a double-layered sac with a combined thickness of 1-2 mm consisting of a thin serosal layer of visceral pericardium adherent to the epicardial layer of the heart and a fibroelastic parietal pericardium, which forms the surrounding sac. The two layers are separated by a potential space containing a thin layer of pericardial fluid derived as a result of ultrafiltration of plasma measuring 15-50 $\mathrm{ml}$ under normal physiological conditions [1, 3, 4]. It has mechanical functions such as serving as a barrier against infection, providing friction-free cardiac motion and limiting distension of the cardiac chambers. It also has immunologic, fibrinolytic and vasomotor properties [3].

Inflammation of the pericardium is a clinical condition with an unpredictable natural history. The condition may range from an acute inflammatory process with or without associated pericardial effusion to chronic thickening and inelasticity of the pericardium, with or without pericardial effusion [4]. Consequently, the restriction of cardiac filling results in one of three pericardial compressive syndromes: constrictive pericarditis, effusive-constrictive pericarditis or cardiac tamponade [1].

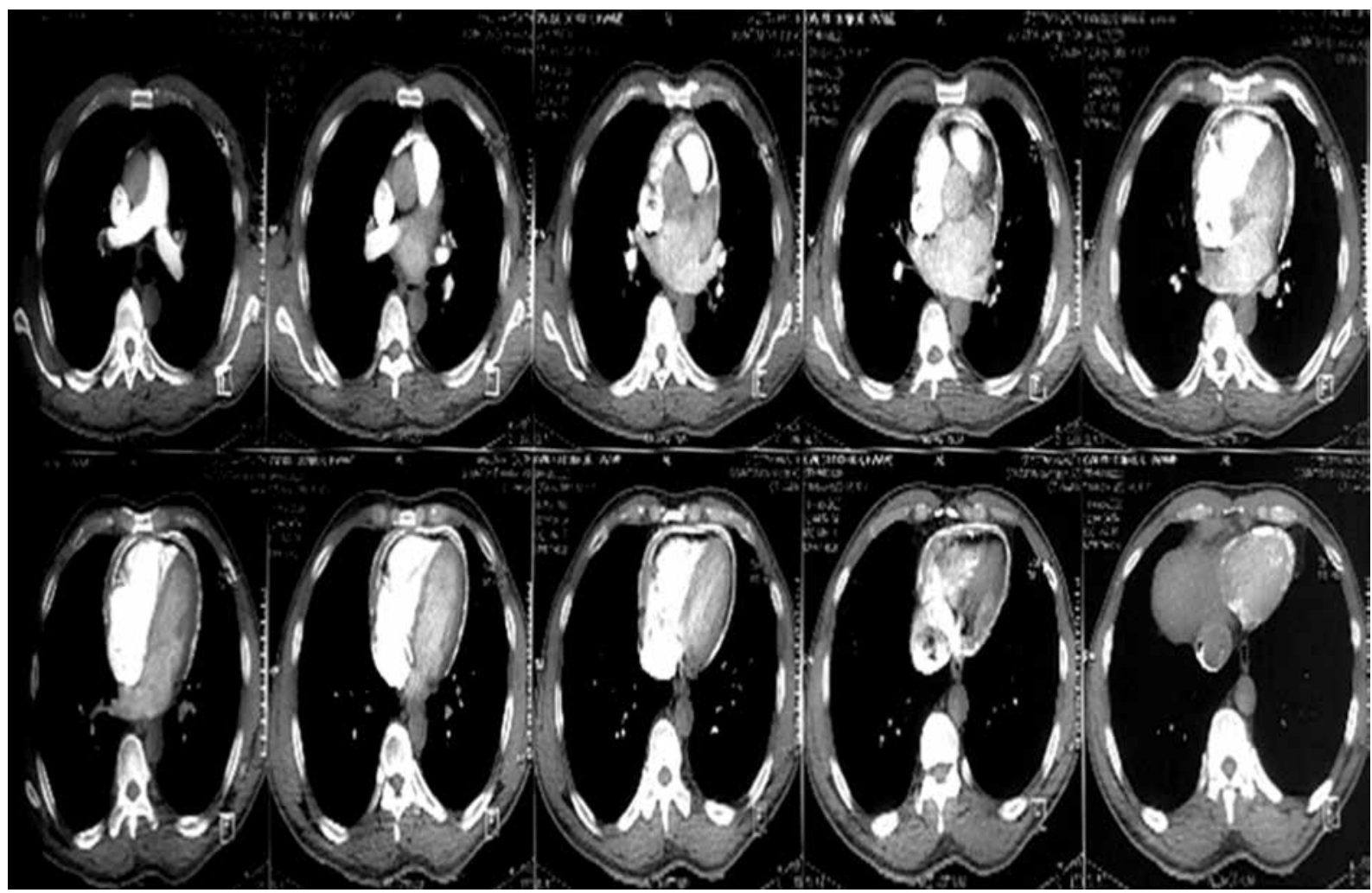

Figure 3. Computed tomography scan of one of the patients showing the calcification ring of calcific constrictive pericarditis 
Table I. Clinico-demographics of the patients

\begin{tabular}{ccccccccccc} 
Case & $\begin{array}{c}\text { Age } \\
\text { [years] }\end{array}$ & Sex & Duration & BP & HR & Ascites & Hepatomegaly & $\begin{array}{c}\text { NYHA } \\
\text { stage }\end{array}$ & $\begin{array}{c}\text { Cardiac } \\
\text { rhythm }\end{array}$ & $\begin{array}{c}\text { Aetiology/pre-op. } \\
\text { TB test }\end{array}$ \\
\hline 1 & 14 & F & 2 months & $120 / 76$ & 122 & Present & Present & NYHA IV & NSR & TB \\
\hline 2 & 2.5 & M & 2 weeks & $92 / 50$ & 140 & Present & Present & NYHA III & NSR & Pyomyositis with sepsis \\
\hline 3 & 2 & M & 2 weeks & $80 / 40$ & 130 & Present & Present & NYHA III & NSR & Sepsis \\
\hline 4 & 8 & M & 2 weeks & $97 / 60$ & 147 & Absent & Present & NYHA III & NSR & Pyomyositis with sepsis \\
\hline 5 & 19 & M & 2 years & $110 / 60$ & 90 & Present & Present & NYHA IV & NSR & TB \\
\hline 7 & 16 & M & 2 months & $110 / 74$ & 84 & Absent & Present & NHYA III & NSR & Negative \\
\hline 8 & 28 & M & 1 year & $110 / 70$ & 96 & Present & Present & NYHA III & NSR & TB \\
\hline 9 & 24 & M & 3 years & $120 / 90$ & 110 & Present & Present & NYHA IV & NSR & Negative \\
\hline 10 & 29 & M & 6 weekths & $83 / 68$ & 126 & Absent & Absent & NYHA IV & AF & Negative \\
\hline
\end{tabular}

NYHA - New York Heart Association, TB - tuberculosis, NSR - normal sinus rhythm, AF - atrial fibrillation, Preop. - preoperative, Postop. - postoperative.

Table II. Pattern of preoperative investigations of the patients

\begin{tabular}{|c|c|c|c|c|c|c|c|c|}
\hline Case & $\begin{array}{l}\text { Pre-op. anti-TB } \\
\text { treatment }\end{array}$ & $\begin{array}{l}\text { Preoperative catheter } \\
\text { pericardiocentesis }\end{array}$ & ECG & CXR & ECHO & $\begin{array}{l}\text { Chest } \\
\text { USG }\end{array}$ & $\begin{array}{l}\text { Chest CT } \\
\text { scan }\end{array}$ & $\begin{array}{l}\text { Abdominal } \\
\text { USG }\end{array}$ \\
\hline 1 & Yes & Yes & No & Yes & Yes & No & No & No \\
\hline 2 & No & Yes & No & Yes & Yes & No & No & No \\
\hline 3 & No & Yes & No & Yes & Yes & No & No & No \\
\hline 4 & No & Yes & No & Yes & No & Yes & No & No \\
\hline 5 & Yes & Yes & Yes & Yes & Yes & Yes & Yes & Yes \\
\hline 6 & Yes & No & Yes & Yes & Yes & No & No & No \\
\hline 7 & Yes & Yes & Yes & Yes & Yes & No & No & No \\
\hline 8 & Yes & No & Yes & Yes & Yes & No & Yes & No \\
\hline 9 & No & No & Yes & Yes & No & No & Yes & Yes \\
\hline 10 & No & No & Yes & No & Yes & No & Yes & No \\
\hline
\end{tabular}

Table III. Intraoperative and post-operative patients' characteristics

\begin{tabular}{|c|c|c|c|c|c|c|c|c|}
\hline Case & $\begin{array}{l}\text { Pericardial } \\
\text { thickness } \\
{[\mathrm{mm}]}\end{array}$ & $\begin{array}{l}\text { Pericardial } \\
\text { effusion }\end{array}$ & $\begin{array}{l}\text { Nature } \\
\text { of pericardial } \\
\text { effusion }\end{array}$ & $\begin{array}{l}\text { Pleural } \\
\text { effusion }\end{array}$ & $\begin{array}{l}\text { Anaesthesia } \\
\text { time [h] }\end{array}$ & $\begin{array}{l}\text { Surgery } \\
\text { time [h] }\end{array}$ & $\begin{array}{l}\text { Post-op. } \\
\text { ventilatory } \\
\text { support }\end{array}$ & $\begin{array}{l}\text { Post-op. } \\
\text { inotropic } \\
\text { support }\end{array}$ \\
\hline 1 & 6.1 & Positive & Haemorrhagic effusion & Negative & 3.35 & 1.52 & No & No \\
\hline 2 & 7.0 & Negative & Negative & Negative & 3.36 & 2.15 & No & No \\
\hline 3 & 4.0 & Positive & Purulent effusion & Left pleural effusion & 4.10 & 1.58 & No & No \\
\hline 4 & 8.0 & Negative & Negative & Negative & 3.20 & 2.15 & No & No \\
\hline 5 & 5.0 & Positive & Serous effusion & Right Pleural effusion & 4.30 & 2.50 & Yes & Yes \\
\hline 6 & 5.0 & Negative & Negative & Negative & 4.31 & 3.15 & No & No \\
\hline 7 & 6.0 & Positive & $\begin{array}{l}\text { Serosanguinous } \\
\text { effusion }\end{array}$ & $\begin{array}{l}\text { Bilateral pleural } \\
\text { effusion }\end{array}$ & 4.37 & 2.59 & No & Yes \\
\hline 8 & 7.0 & Negative & Chocolate effusion & Right pleural effusion & 4.45 & 4.17 & Yes & Yes \\
\hline 9 & 4.0 & Positive & Chocolate effusion & Left pleural effusion & 3.40 & 2.26 & No & No \\
\hline 10 & 5.0 & Negative & Negative & Negative & 3.10 & 2.32 & No & No \\
\hline
\end{tabular}

From the current study, 5 (50\%) of our patients including 2 of the 3 children had effusive-constrictive pericarditis, $3(30 \%)$ had annular constrictive pericarditis with 2 (20\%) patients having calcific constrictive pericarditis as shown in Figure 4.

Constrictive pericarditis is the endpoint of the natural history of acute pericarditis of different aetiologies where a chronic inflammatory process results in a thickened, fibrotic and inelastic pericardium with consequent impairment of diastolic function and systemic congestion [3, 5-7]. Effusive-constrictive pericarditis, a variant of constrictive pericarditis, is characterized by concurrent presence of visceral pericardial constriction and pericardial effusion. There is little to no relief of the tamponade physiology 
Table IV. Post-operative course and follow-up

\begin{tabular}{|c|c|c|c|c|c|}
\hline Case & Complications & $\begin{array}{l}\text { Post-op. days } \\
\text { before discharge }\end{array}$ & $\begin{array}{l}\text { Histopathology } \\
\text { report }\end{array}$ & Follow-up & Outcome \\
\hline 1 & Right heart failure & 6 & Consistent with $\mathrm{CP}$ & 1.5 month & Dead \\
\hline 2 & $\begin{array}{l}\text { Right femoral central venous } \\
\text { catheter fracture }\end{array}$ & 8 & Consistent with $\mathrm{CP}$ & 8 months & Alive \\
\hline 3 & Nil & 5 & Consistent with CP & 11 months & Alive \\
\hline 4 & Nil & 5 & Lost & 6 months & Alive \\
\hline 5 & Nil & 8 & Lost & 55 months & Alive \\
\hline 6 & Nil & 8 & Consistent with CP & 31 months & Alive \\
\hline 7 & Nil & 7 & Lost to Follow-Up & 46 months & Alive \\
\hline 8 & Nil & 12 & Consistent with $\mathrm{CP}$ & 3 months & Alive \\
\hline 9 & Nil & 6 & Consistent with $\mathrm{CP}$ & 28 months & Alive \\
\hline 10 & Superficial wound site infection & 4 & Consistent with CP & 2 months & Alive \\
\hline
\end{tabular}

$\mathrm{CP}$ - constrictive pericarditis.
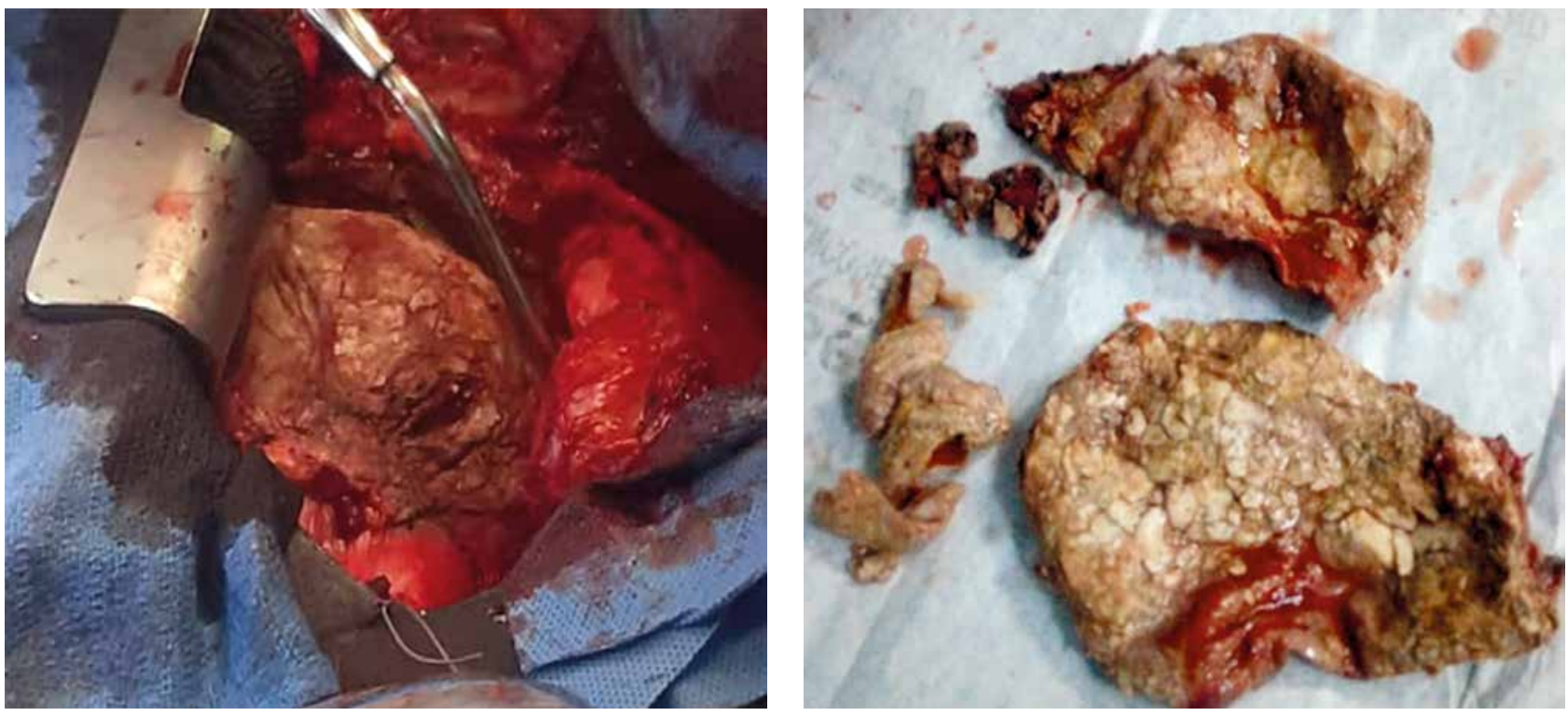

Figure 4. Intraoperative photo showing the calcific pericardium in situ and after excision

upon drainage of the pericardial effusion [8, 9]. Imazio et al. studied the overall risk of developing constrictive pericarditis following a bout of acute pericarditis and they found it to be generally rare with a $1.8 \%$ likelihood of progression. However, the risk varied significantly depending on the aetiology [10].

\section{Aetiology}

Despite constrictive pericarditis being the endpoint in the natural history of any pericardial disease, the main causes identified are idiopathic, post-infectious (viral or bacterial), post-cardiotomy irritation, post-mediastinal irritation and miscellaneous cases such as malignancy, uraemic pericarditis, trauma and sarcoidosis $[1,5]$. Post-infectious pericarditis is most commonly due to viruses (viral pericarditis) such as coxsackie virus and bacteria (bacterial or purulent pericarditis) such as Mycobacterium tuberculosis, Staphylococcus spp., Haemophilus spp. and Streptococcus spp. [4]. In the past, tuberculosis accounted for about half of all confirmed cases of constrictive pericarditis globally $[1,10,11]$ but now the majority of constrictive pericarditis cases occurring in developed countries are idiopathic or following cardiac surgery or mediastinal irradiation [1, 3, 7,12 ] for conditions such as Hodgkin's lymphoma or breast cancer $[1,5]$. A single tertiary centre retrospective study by Porta-Sanchez et al. spanning 34 years showed aetiology to be idiopathic in $54 \%$ of cases while post-infectious constrictive pericarditis accounted for $17 \%$ of the cases with $10 \%$ being due to tuberculosis. Post-cardiotomy and postradiotherapy constrictive pericarditis were responsible for $4 \%$ and $2 \%$ respectively [13]. In contrast to this observation, the present study found that only 3 patients out of the ten cases tested positive for TB, as shown in Table I, although 5 of the patients received anti-TB treatment before surgery. The decision to treat the two patients who tested negative for TB (via sputum for acid-fast bacilli and GeneXpert analysis) was based on a high clinical suspicion. However, all the 3 children reported in this study had septic focus 
leading to the development of purulent pericarditis and subsequently to constrictive pericarditis over a relatively short period. Two of the 3 children had pyomyositis of the thigh and the other one had septicaemia consequent to Staphylococcus aureus infection.

It should be mentioned here that tuberculosis is still the most common cause of constrictive pericarditis in developing countries, particularly in tuberculosis and HIV-endemic areas $[3,7,10,14]$. A retrospective study over 22 years by Mutyaba et al. [14] from South Africa found tuberculous pericarditis to be either the suspected or proven cause of constrictive pericarditis with a prevalence of $90.9 \%$. This is in contrast with our observation in our current study where $30 \%$ of our studied subjects presented with confirmed tuberculous constrictive pericarditis. The observed low incidence is likely to be due to the demography of our studied population in which 4 (40\%) of the children had septic focus as the primary cause of the purulent pericarditis. However, the observed outcome of the current study seems to be consistent with a study by Mutyaba et al. in Cape Town, South Africa, who reported an incidence of $32.7 \%$ [14]. Furthermore, a similar result was obtained by Tettey et al., from Ghana, which indicated that tuberculosis was responsible as a primary cause of constrictive pericarditis accounting for about $63.6 \%$ of the cases studied between 2000 to 2005 in Accra, Ghana [15] with a similar study period as our own (5 years), although they had 11 patients as compared to our 10 patients.

Recent data have established that one major risk factor that accounts for the evolution of an acute pericarditis to a constrictive pericarditis is the underlying aetiology, and purulent pericarditis has been shown to have the greatest risk of evolution to constriction compared to other aetiologies $[6,10]$. They also tend to have an acute course to constriction over a shorter time interval of about 8 days, as reported in a study by Porta-Sanchez et al. This was consistent with our findings in all the 3 cases in our current study involving children who had sepsis. All the subjects progressed from acute pericarditis to purulent pericardial effusion for which catheter pericardiocentesis was performed but finally progressed quickly to constrictive pericarditis and as such had to undergo pericardiectomy. It should be mentioned here that idiopathic forms, on the other hand, tend to have a chronic course to the constrictive phase [13].

\section{Pathophysiology}

With a normal pericardium, the inspiratory drop in intrathoracic pressure results in an increased venous return that is subsequently accommodated by pericardial distension and slight leftward interventricular septal deviation. In constrictive pericarditis, where there is chronic scarring and fibrosis of the pericardium, there is no intra-cardiac transmission of the inspiratory drop in intrathoracic pressure. Also, the inelastic pericardium limits cardiac filling particularly in mid-to-late diastole. This along with the exaggerated left-ward interventricular septal shift accounts for the increased drop in systolic blood pressure in inspiration defined as pulsus paradoxus [1, 3]. Due to the limitation in diastolic filling, persistence into chronicity leads to systemic congestion, as seen in right-sided heart failure [12, 16], presenting as ascites, peripheral oedema and tender hepatomegaly.

\section{Clinical presentation}

Clinical symptoms associated with constrictive pericarditis are usually due to fluid overload and systemic congestion as well as reduced cardiac output [1]. Heart failure is commonly seen in over $60 \%$ of cases, with exertional dyspnoea and oedema being commonly reported [11]. The study by Tettey et al. in 2007, observed that 8 out of their 11 patients were in class III NYHA classification preoperatively. Similarly, Mutyaba et al. also reported in their retrospective study that 80 out of the 121 patients, representing $66 \%$, were in NYHA functional class III or IV preoperatively. As shown in Table I, in the current study 6 out of the 10 patients presented in NYHA class III. As shown by Figure 1 , in 1 of the patients, systemic congestion resulted in tender hepatomegaly, peripheral oedema, ascites, early satiety and anorexia $[3,7,11,12,16]$. The majority of patients present with elevated jugular venous pressure with sleepy descent on the waveform due to the rapid early diastolic filling [1, 11]. Kussmaul sign, that is an increase in jugular venous distension on inspiration, has also been found to be associated with constrictive pericarditis. Pulsus paradoxus is seen in less than $20 \%$ of cases [1]. Cardiac auscultation commonly reveals diminished or distant heart sounds [16]. Six $(60 \%)$ of the cases in our current study presented with ascites and 9 (90\%) out of the ten cases presented with tender hepatomegaly, as shown in Table I.

\section{Diagnostic investigations}

Chest X-ray in patients with constrictive pericarditis may show small or normal cardiac size but presence of cardiomegaly does not rule out constriction [7]. Presence of pericardial calcification - best seen on anterior, oblique or lateral views - is highly suggestive of chronic constrictive pericarditis [1]. However, it has been reported in less than $30 \%$ of surgically confirmed cases of constrictive pericarditis $[11,13,16]$. This is consistent with our current study where 2 (20\%) out of the ten cases studied showed calcification on both the chest and CT scan, as shown in Figures 2 and 3. Far superior diagnostic yields are achieved with the use of echocardiogram, cardiac CT or magnetic resonance imaging (MRI) [13]. Cardiac CT scan or MRI provides a better assessment of pericardial thickness and calcifications and visualization of any abnormal ventricular contours caused by the constriction [11, 16]. Echocardiography features indicative of constrictive physiology include respiration-related ventricular septal shift, preserved or increased medial mitral annular e-velocity and prominent hepatic vein expiratory diastolic flow reversals [17]. Currently, the use of cardiac catheterization in the diagnosis of constrictive pericarditis is decreasing due to the increased diagnostic accuracy of echocardiography, CT scan- 
ning and MRI [13]. However, cardiac catheterization is the gold standard for diagnosis in the event of indeterminate findings with the non-invasive tests [11]. The current study employed two main modalities to confirm the diagnosis of constrictive pericarditis, namely chest CT scan and echocardiography with supporting evidence from chest X-ray and ECG. Six (60\%) out of the 10 patients had ECG, 9 had chest X-ray, 8 had echocardiography and 4 had chest CT scan. Three (30\%) had confirmation of the diagnosis from both echocardiography and chest CT scan, as shown in Table II.

\section{Surgical treatment}

Pericardiectomy remains the definitive treatment for constrictive pericarditis [1, 15]. Various approaches have been described, with the most favoured approach being median sternotomy $[5,15]$. Median sternotomy has the advantage of providing easy access to right cardiac chambers and left ventricle, allowing a more extensive pericardiectomy and also being optimal in the event of a need for cardiopulmonary bypass. It is also the indicated approach in the event of pericardial calcification [7]. It is highly patronized as reported by Tettey et al. [15] from Ghana, where all 11 patients underwent pericardiectomy via median sternotomy. This is similar to our current study, where all the 10 patients underwent pericardiectomy via median sternotomy. Bertog et al. and Yangni-Angate et al. employed median sternotomy as their approach in $90 \%$ and $97.5 \%$ of their cases respectively $[5,7]$. One patient in our study initially presented with serous pericardial effusion for which catheter pericardiocentesis was performed with a size 7Fr pericardiocentesis catheter. He subsequently developed a recurrent pericardial effusion 2 months later confirmed by chest ultrasound and echocardiography with minimal fibrin deposits. He underwent a pericardial window via left posterolateral thoracotomy. The pericardium was then not found to be thickened. Six months later, he presented with symptomatic constrictive pericarditis (ascites, pedal oede$\mathrm{ma}$ and raised jugular venous pressure in NYHA class III) confirmed by echocardiography for which pericardiectomy via median sternotomy was performed. Other surgical approaches that have been adopted in various studies include a left anterolateral thoracotomy, bilateral anterior thoracotomy or the Harrington approach [3, 5, 7, 15]. Both bilateral anterior thoracotomy and the Harrington approach are currently not used in clinical practice [15]. The left anterolateral thoracotomy is particularly invaluable in cases with purulent pericarditis or effusive-constrictive pericarditis so as to avoid sternal osteomyelitis postoperatively [3].

Pericardiectomy is deemed total when decortication is carried out from the midline spanning laterally to within $1 \mathrm{~cm}$ of the phrenic nerves bilaterally along with the diaphragmatic pericardium [3, 7]. Radical pericardiectomy involves decortication of all surfaces of the heart. This procedure may be associated with increased complications [7]. Conventionally, the left ventricle is decorticated first before the right ventricle so as to prevent the occurrence of pulmo- nary oedema [3]. In cases with dense epicardial adhesions or calcifications in which decortication could result in inadvertent perforation of the underlying chamber, the waffle procedure - where longitudinal and transverse incisions of the visceral pericardium are made - could be employed [3, 7]. All our patients underwent total pericardiectomy.

Despite the significant improvement in functional status and excellent survival rates, pericardiectomy is associated with significant perioperative mortality [1, 3]. Mortality rates ranging between $12 \%$ and $15 \%$ have been reported by Mutyaba et al. and Yangni-Angate et al. [7, 14]. Tettey et al., however, reported no mortality among the 11 patients who underwent pericardiectomy [15]. In contrast to zero mortality from Tettey et al. and consistent with reports from Mutyaba et al. and Yangni-Angate et al., we had one patient dying of heart failure in 6 weeks after surgery, giving a late mortality rate of $10 \%$. A strong correlation however has been established between the operative mortality rate and the NYHA functional classification of the patient preoperatively as well as the aetiology of the pericardial constriction [1, 3]. The patient who died was in NYHA class IV on admission with massive ascites, tender hepatomegaly and pericardial constriction.

\section{Conclusions}

Surgical pericardiectomy via median sternotomy is still the standard modality of treatment for constrictive pericarditis, and this can be done without cardiopulmonary bypass and inotropic support, especially in a resourceconstraint setting, with excellent results. The commonest cause of paediatric constrictive pericarditis in our environment was found to be non-tuberculous bacterial infections from a septic focus.

Limitations of the study: Our study had a small sample size.

\section{Acknowledgments}

We are very grateful to the patients for the publication of these cases and the accompanying images and all the theatre staff of the cardiovascular and thoracic surgery unit.

\section{Disclosure}

The authors report no conflict of interest.

\section{References}

1. Constrictive pericarditis - UpToDate [Internet]. 2017 [cited 2020 Jun 3]. Available from: https://www.uptodate.com/contents/constrictive-pericarditis? search $=$ constrictive pericarditis $\&$ source $=$ search_result $\&$ selectedTitle $=1 \sim 10$ 9\&usage_type=default\&display_rank $=1$

2. Ling LH, Oh JK, Schaff HV, Danielson GK, Mahoney DW, Seward JB, Tajik AJ. Constrictive pericarditis in the modern era: evolving clinical spectrum and impact on outcome after pericardiectomy. Circulation 1999; 100: 1380-1386.

3. Depboylu BC, Mootoosamy P, Vistarini N, Testuz A, El-Hamamsy I, Cikirikcioglu M. Surgical treatment of constrictive pericarditis. Texas Hear Inst J 2017; 44: 101-106.

4. Ramasamy V, Mayosi BM, Sturrock ED, Ntsekhe M. Established and novel pathophysiological mechanisms of pericardial injury and constrictive pericarditis. World J Cardiol 2018; 10: 87-96. 
5. Bertog SC, Thambidorai SK, Parakh K, Schoenhagen P, Ozduran V, Houghtaling PL, Lytle BW, Blackstone EH, Lauer MS, Klein AL. Constrictive pericarditis: etiology and cause-specific survival after pericardiectomy. J Am Coll Cardiol 2004; 43: 1445-1452.

6. Imazio M, Gaita F. What's new in constrictive pericarditis? A European perspective. Rev Esp Cardiol 2015; 68: 1059-1060.

7. Yangni-Angate KH, Tanauh Y, Meneas C, Diby F, Adoubi A, Diomande M. Surgical experience on chronic constrictive pericarditis in African setting: review of 35 years' experience in Cote D'Ivoire. Cardiovasc Diagn Ther 2016; 6 (Suppl 1): S13-S19.

8. Salami MA, Adeoye PO, Adegboye VO, Adebo OA. Presentation pattern and management of effusive-constrictive pericarditis in Ibadan. Cardiovasc J Afr 2012; 23: 206-211.

9. Sagrista-Sauleda J, Angel J, Sanchez A, Permanyer-Miralda G, Soler-soler J. Effusive-constrictive pericarditis. N Engl J Med 2004; 350: 469-475.

10. Imazio M, Brucato A, Maestroni S, Cumetti D, Belli R, Trinchero R, Adler Y. Risk of constrictive pericarditis after acute pericarditis. Circulation 2011; 124 1270-1275.

11. Welch TD, Oh JK. Constrictive pericarditis: old disease, new approaches. Curr Cardiol Rep 2015; 17: 20.
12. Sabiston \& Spencer Surgery of the Chest. $9^{\text {th }}$ ed. Sellke FW, del Nido PJ, Swanson SJ (eds.). Elsevier, Philadelphia 2016; 113-115.

13. Porta-Sánchez A, Sagristà-Sauleda J, Ferreira-González I, Torrents-Fernández A, Roca-Luque I, García-Dorado D. Constrictive pericarditis: etiologic spectrum, patterns of clinical presentation, prognostic factors, and longterm follow-up. Rev Espańola Cardiol 2015; 68: 1092-1100.

14. Mutyaba AK, Balkaran S, Cloete R, Du Plessis N, Badri M, Brink J, Mayosi BM. Constrictive pericarditis requiring pericardiectomy at Groote Schuur Hospital, Cape Town, South Africa: causes and perioperative outcomes in the HIV era (1990-2012). J Thorac Cardiovasc Surg 2014; 148: 3058-3065.

15. Tettey M, Sereboe L, Aniteye E, Edwin F, Kotei D, Tamatey M, Entsua-Mensah K, Frimpong-Boateng K. Surgical management of constrictive pericarditis. Ghana Med J 2007; 41: 190-193.

16. Brunicardi CF, Andersen DK, Billiar TR, Dunn DL, Hunter JG, Matthews JB, Pollock RE. Schwartz's Principles of Surgery. 10 th ed. McGraw-Hill 2015; 695-698.

17. Welch TD, Ling LH, Espinosa RE, Anavekar NS, Wiste HJ, Lahr BD, Schaff HV, Oh JK. Echocardiographic diagnosis of constrictive pericarditis Mayo Clinic criteria. Circ Cardiovasc Imaging 2014; 7: 526-534. 